\title{
Managing business crisis resulting from the coronavirus
}

\author{
Mehrsa Bakhtiyari ${ }^{1}$ \\ ${ }^{1}$ Affiliation not available
}

April 28, 2020

\begin{abstract}
The novel coronavirus, also known as COVID-19, has infected at least 1 million persons worldwide. It has also accounted for a number of deaths. No doubt, it has dealt a drastic blow to businesses and the global economy, leaving behind a huge crisis. Thus, the present study discusses management strategies to counter the short and long-term effects of the COVID-19 pandemic on businesses.
\end{abstract}

\section{Introduction}

The novel coronavirus pneumonia is an acute respiratory disease. In December 2019, this disease emerged in Wuhan, China. The Chinese government called it SARS-CoV-2 which was subsequently named COVID19 by the World Health Organization (WHO) [1]. In January 2020, WHO confirmed it as a sustained human to human disease [2]. The World Health Organization has declared Covid-19 a full-blown pandemic, which means it's a crisis-level disease outbreak in multiple countries. This disease is extremely rare and its unexpected occurrence has major consequences for just about everybody. Covid-19 is similar to past zoonotic coronaviruses, including SARS. It's less lethal than SARS, but spreads more easily. The death rate is under 2 percent, and for people under the age of 60 under 1 percent.

In a bid to control its spread, this disease has led to flight cancellations, border closure, postponement of business meetings and so on. In fact, the impact of this pandemic will take years to be fully quantified. Social distancing - basically keeping people away from each other (as well as avoiding human physical contact and washing hands) has been one of the mostly talked about method of preventing a full-scale outbreak. However, this has led to severe consequences to businesses and even job losses. This is because business is usually conducted by bringing people together, not keeping them apart. People come to work, have meetings, travel to meet with clients, attend trade conferences and purposefully interact with each other to forward the interests of the organization. Thus, this brings to concern how to keep business alive while keeping people apart. No doubt, the COVID-19 pandemic has led to huge economic and business crisis. For instance, oil prices crashed to an 18-year low of $\$ 20.09$ a barrel, thereby sending a devastating blow to energy demand. In view of the imminent crisis to businesses, it is imperative that efficient management strategies are adapted to this unusual and unpleasant situation. Thus, the present study highlights these key approaches.

\section{Immediate steps}

To prevent further escalation of the situation, the following first steps should be observed. They are as follows:

Appoint a crisis response team that meets daily.

Monitor government, medical, industry and local sources for updates for the team.

Implement a communications plan to transparently inform all employees.

Develop and implement a comprehensive crisis response. 
- Develop or update, then communicate and enforce, a remote-work policy.

\section{Long-term actions}

\section{Scenario planning}

- Organizations must act with imperative when developing and implementing enhanced risk management practices, focusing on the opportunities scenario planning offers in creating pre-emptive action plans.

- Scenarios enable organizations to see the bigger picture and make effective trade-off decisions on issues like: how much stock to hold - and where, or how to balance the cost of inventory versus the cost of failing to satisfy customers. Simulations can be run swiftly to identify "sweet spots" between apparently conflicting objectives, based on real-time inventory data, customer demand, and supplier capability. Increasingly enabled by AI and automation, these scenarios can help prescribe rather than just predict.

By analyzing past events and hypothesizing future threats, organizations are able to identify strategic and concentrated supplies that are at risk in major crises, and most importantly, recognize when current internal risk capacities prove insufficient.

\section{Supplier risk management}

Real-time supplier data such as system performance category alerts and geopolitical events helps manage performance and issue resolution.

When alerted, proactive measures should be taken by organizations to uncover additional exposure levels by reaching out to suppliers (from tier 1, tier 2 and below) outside of affected regions to identify upstream supply dependencies within their supply chains.

Further, organizations could benefit from balancing supply and demand and working with internal stakeholders as well as critical suppliers to contractually agree on logistic-based costs and necessary buffer stock, so as to reduce sudden price increases in the face of a crisis.

\section{Technology upgrades}

- In line with the technology-enabled business climate we currently operate in, organizations should rethink the way their employees collaborate with each other and customers - within the office, regionally and globally.

By investing in internal technology, organizations can teach employees how to effectively leverage powered execution tools such as cloud-office technology and zero-touch models. This will help ensure that not only in times of crisis are teams better equipped to work remotely, but as the business environment continues to shift, employees are able to adapt alongside it and continue serving customers.

\section{Conclusion}

In conclusion, as the novel coronavirus continues to take its toll on businesses as well as the global economy, hope is not lost for business to bounce back strongly. However, this can only be achieved by ensuring that effective short and long-term management strategies are implemented and followed to the letter.

\section{References}

1. Chan JF-W, Yuan S, Kok K-H, To KK-W, Chu H, Yang J, et al. A familial cluster of pneumonia associated with the 2019 novel coronavirus indicating person-to-person transmission: a study of a family cluster. Lancet. 2020;395(10223):514-23.

2. Organization WH. Coronavirus disease 2019 (COVID-19) situation report-34. Geneva, Switzerland: World Health Organization; 2020. 